\title{
Разработка информационной системы для описания наблюдений за фенотипическими признаками сельскохозяйственных растений
}

\author{
Молодияов B.B., cm.nреп., НГУ, г. Новосибирск, Россия, vv@fen.nsu.ru \\ Афонников Д.А. *, к.б.н., в.н.с., ИЦиГ СО РАН, г. Новосибирск, Россия \\ *e-mail:ada@bionet.nsc.ru
}

Разработана компьютерная система 'Observer', которая позволяет осуществлять сбор данных по селекиионно-генетическим экспериментам, полученных, прежде всего, в результате полевого мониторинга посевов. Ее структура позволяет гибким образом формировать описание признаков растений и мест проведения эксперимента, учитывать условия среды и даты проведения измерений.

Ключевые слова: селекичонно-генетический эксперимент, фенотипирование растений, полевые наблюдения, база данных.

\section{Information system for collecting and storing phenotypic observation in crop plants}

Molodtsov V.V., senior lecturer, NSU, Novosibirsk, Russia,vv@fen.nsu.ru Afonnikov D.A., kand.biol.sci., leading researcher, ICG SB RAS, Novosibirsk, Russia,ada@bionet.nsc.ru

The information system 'Observer' developed for collection and storing of the data for breeding experiment, mostly from field observations. The structure of the system allows to describe wide range of plant phenotypic traits, locations, environment anв measurement time.

Key words: breeding experiment, plant phenotyping, field observations, database.

Современные селекционно-генетические эксперименты по созданию новых сортов и гибридов сельскохозяйственных растений опираются на использование информации как о генотипах растений, так и их фенотипов, а также условиях окружающей среды [1]. Данные наблюдений за растениями могут быть использованы для моделирования урожая с использованием современных математических и численных методов [2]. Фенотипические данные разнообразны, могут описывать десятки характеристик растений и измеряются в течение всей вегетации. Для селекционера измерения этих признаков происходят в полевых условиях и заносятся в полевой журнал наблюдений. Ведение таких журналов рутинная и трудоемкая процедура. В этой связи, создание технологий эффективного сбора данных о полевых наблюдениях и фенотипических признаках растений является актуальной задачей. 
Для решения этой задачи в работе была разработана база данных “Observer” для хранения информации о фенотипических признаках растений, измеренных в процессе вегетации.

Данная система в качестве объекта исследований использует делянку растений, для которой определены географические координаты и название месторасположения. Для делянки определена структура данных “Эксперимент”, которая хранит информацию об измерении различных фенотипических характеристик растений, включая фенологические данные, характеристики урожайности, степень повреждения растений патогенами и вредителями (рис.1).

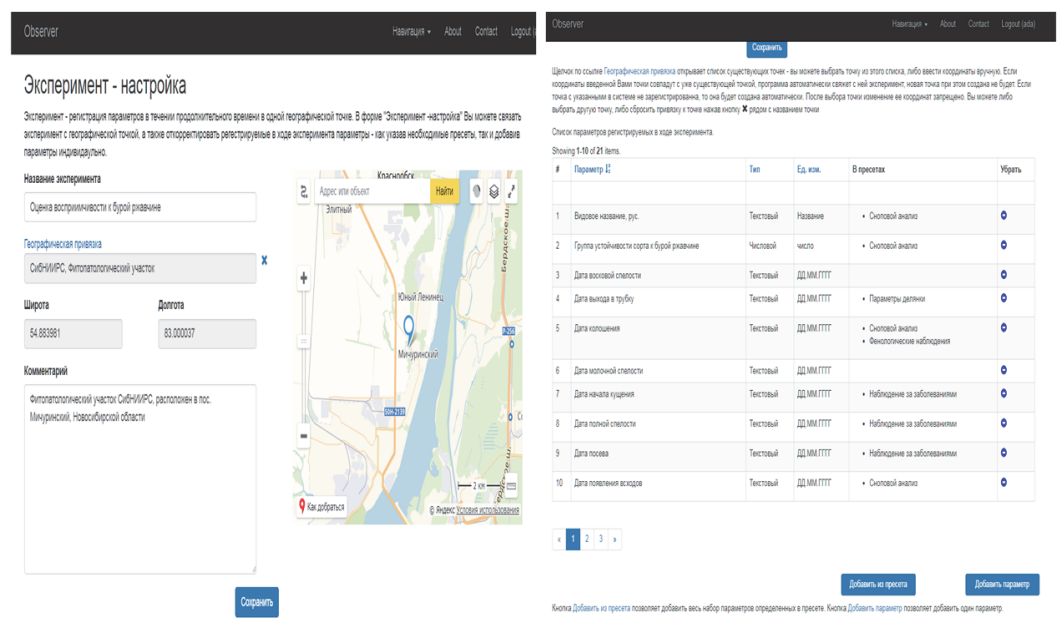

Рисунок 1. Настройка эксперимента: слева представлена страница создания эксперимента; справа - страница формирования параметров растений.

Наблюдения над растениями в эксперименте характеризуются датой, набором параметров, а также их значениями. Для эксперимента определяется заранее заданный набор параметров, каждый из которых задан следующими характеристиками: название, тип (числовой или текстовый), единицей измерения. Для параметра также определяется его принадлежность к блоку параметров, несколько параметров могут быть объединены в блок. Один параметр может находиться в нескольких блоках. Такая группировка параметров является удобной для описания групп фенотипических, генетических признаков и признаков окружения. Например, в текущей версии базы данных мы определили блок параметров, который характеризует воздействие патогена на растение и реакцию растения (рис. 2): группа устойчивости сорта к бурой 
ржавчине; индекс устойчивости к бурой ржавчине; латентный период поражения бурой ржавчиной; патотип патогена; поражение листовой пластинки бурой ржавчиной; тип реакции на бурую ржавчину; уровень устойчивости к бурой ржавчине; устойчивость сорта к бурой ржавчине.

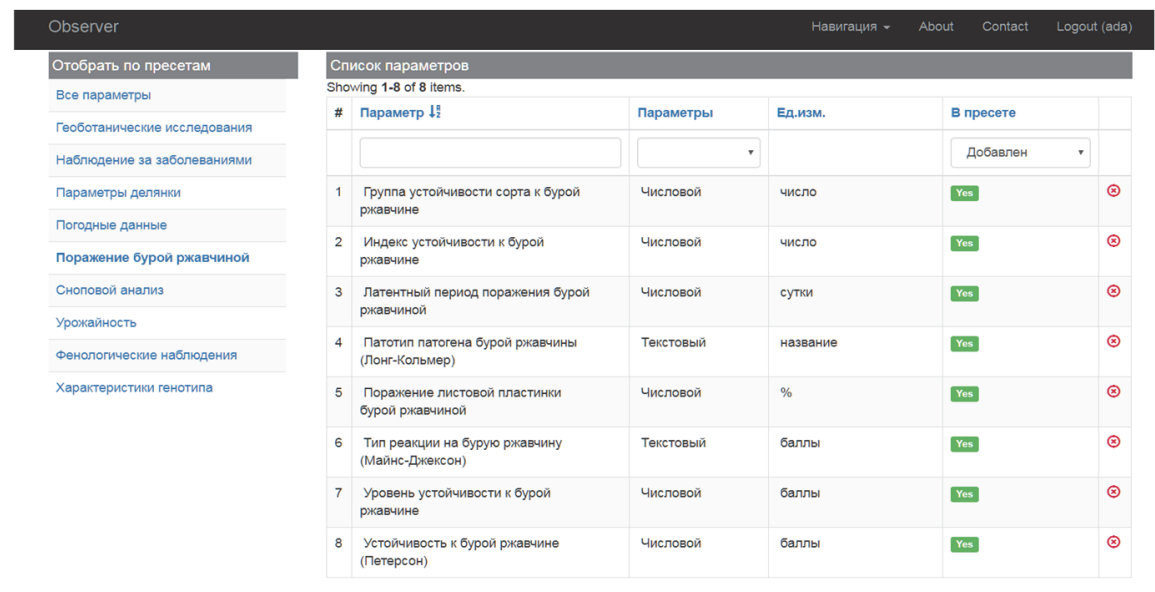

Щелчок по флажку "В пресете" изменит статус.

Рисунок 2. Набор параметров, характеризующие взаимодействия патоген-хозяин для бурой ржавчины (P. triticina) и пшеницы в системе сбора и хранения данных.

Большое разнообразие фенотипических характеристик, проведение экспериментов в разных лабораториях и географических точках обуславливают актуальность стандартизации описания фенотипических параметров растения, условий среды и селекционно-генетического эксперимента. Для решения данной проблемы мы использовали дополнительное описание фенотипических признаков растений, представленных в виде онтологий, структурированных и контролируемых словарей биологических терминов [3]. Описания онтологий взяты на сайте pecypca CropOntology (www.cropontology.org).

В системе также реализована возможность интеграции фенотипических данных с результатами метеонаблюдений, которые могут быть получены через Web c ближайшей к месту проведения эксперимента метеостанции.

Разработанная система позволяет автоматизировать сбор информации о результатах наблюдений и оценки фенотипических параметров в процессе выполнения селекционно-генетических экспериментов.

Благодарности: Работа выполнена при поддержке РФФИ (проект № 17-29-08028). При создании базы данных и информационной системы использовались вычислительные ресурсы ЦКП «Биоинформатика» при поддержке бюджетного проекта №0324-2019-0040-С-01. 


\section{Список литературь}

1. Афонников Д.А. и др. Методы высокопроизводительного фенотипирования растений для массовых селекционно-генетических экспериментов // Генетика. -2016. - T. 52. - №. 7. - C. 788-803.

2. Brisson N. et al. An overview of the crop model STICS. // Eur. J. Agron. 2003. - V. 18 - № 3-4 - P. 309-332.

3. Shrestha R. et al. Bridging the phenotypic and genetic data useful for integrated breeding through a data annotation using the Crop Ontology developed by the crop communities of practice //Frontiers in physiology. - 2012. - T. 3. - C. 326.

DOI 10.18699/GPB2020-52

\section{Межсортовая хромосомная изменчивость рапса}

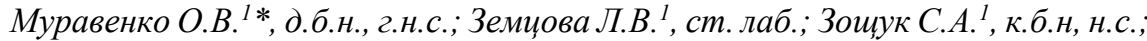
Воловик B.T. ${ }^{2}$, к.с.-х.н., зав.отд.; Юркевич O.Ю. ${ }^{1}$, к.б.н, н.с.; Саматадзе T.E. ${ }^{l}$, к.б.н, н.с.; Амосова А.B. ${ }^{l}$, к.б.н, с.н.с.

${ }^{I}$ ФБУУН Институт молекулярной биологии им. В.А. Энгельгардта РАН, Москва, Российская Федерачия;

${ }^{2}$ ФГБНУ Федеральный научный иентр кормопроизводства и агроэкологии им. В.Р. Вильямса, Московская область, г. Лобня, Российская Федерация. *e-mail:olgmur1@yandex.ru

Впервые исследована хромосомная изменчивость у сортов рапса, произрастающих в районах рискованного земледелия. Анализ структуры кариотипов и хромосомного распределения $45 S$ и $5 S$ рДНК выявил наличие полиморфных вариантов хромосом по локализации и числу этих маркеров в $A$ - $u$ C-субгеномах рапса. Наиболее часто такие полиморфные варианты наблюдались на 1, 3 и 4 парах гомологичных хромосом А-субгенома. В кариотипах растений некоторых сортов выявлен гетероморфизм гомологов, который также чаще обнаруживался на хромосомах А-субгенома. Наши результать указывают на повыленный уровень хромосомного полиморфизма в озимых сортах рапса, по сравнению с яровыми.

Ключевые слова: Brassica napus ssp. oleifera (DC.) Metzg., кариотип, FISH, хромосомный полиморфизм.

\section{Chromosomal variability in rapeseed varieties}

Muravenko O.V. ${ }^{1}$, Zemtsova L.V. ${ }^{1}$, Zoshchuk S.A. ${ }^{l}$, Yurkevich O.Yu. ${ }^{l}$, Volovik V.T. ${ }^{2}$, Samatadze T.E. ${ }^{1}$, Amosova A.V. ${ }^{1}$

${ }^{1}$ Engelhardt Institute of Molecular Biology, Russian Academy of Sciences, Moscow, Russian Federation E-mail olgmur1@yandex.ru

${ }^{2}$ Federal Williams Research Center of Forage Production and Agroecology, Lobnya, Moscow region, Russian Federation. 